\title{
Doxorubicin selectively induces apoptosis through the inhibition of a novel isoform of Bcl-2 in acute myeloid leukaemia MOLM-13 cells with reduced Beclin 1 expression
}

\author{
MILAN VU, NICK KASSOUF, ROSEMARY OFILI, TORBEN LUND, CELIA BELL and SANDRA APPIAH \\ Department of Natural Sciences, Faculty of Science and Technology, Middlesex University, London NW4 4BT, UK
}

Received November 4, 2019; Accepted April 6, 2020

DOI: 10.3892/ijo.2020.5052

\begin{abstract}
The overexpression of anti-apoptotic Bcl-2 in acute myeloid leukaemia (AML) may contribute to difficulties in eradicating these cells during chemotherapy. In the present study, doxorubicin (Dox) was evaluated for its potential to induce selective apoptotic cell death in AML MOLM-13 cells and to modulate autophagy through $\mathrm{Bcl}-2$ and Beclin 1 protein expression. Annexin V/propidium iodide and 5(6)-carboxyfluorescein diacetate succinimidyl ester (CFSE) flow cytometric analyses were conducted to determine the effects of Dox on cell death and cell proliferation, respectively, following $48 \mathrm{~h}$ of co-incubation with AML MOLM-13 or U-937 monocytic cells. The protein expression levels of Bcl-2 and Beclin 1 in untreated and treated cells were quantified by western blot analysis. Dox reduced the viability of MOLM-13 cells partly by inhibiting cell division and inducing cell apoptosis. Dox demonstrated a level of selectivity in its cytotoxicity against MOLM-13 compared to U-937 cells $(\mathrm{P}<0.05)$. Dox induced a significant decrease in Beclin 1 protein levels in MOLM-13 cells without significantly affecting the protein levels in U-937 monocytes. A novel Bcl-2 15-20 kDa (p15-20-Bcl-2) isoform was found to be selectively expressed in AML MOLM-13 cells (but absent in the leukaemic cell lines tested, OCI-AML2, CML K562 and U-937). Dox induced a highly significant inhibition of p15-20-Bcl-2 at concentrations of $0.5,0.75$ and $1 \mu \mathrm{M}(\mathrm{P}<0.01)$. However, the usual $26 \mathrm{kDa}$ Bcl-2 (p26-Bcl-2- $\alpha)$ isoform protein expression was not affected by the drug in either the MOLM-13 or U-937 cells. It was thus postulated that Dox exhibited some selectivity by targeting the p15-20-Bcl-2 isoform in MOLM-13 cells and activating Beclin 1 to induce cell death.
\end{abstract}

Correspondence to: Dr Sandra Appiah, Department of Natural Sciences, Faculty of Science and Technology, Middlesex University, The Burroughs, Hendon, London NW4 4BT, UK

E-mail: s.appiah@mdx.ac.uk

Key words: doxorubicin, acute myeloid leukaemia, Bcl-2, Beclin 1, 5(6)-carboxyfluorescein diacetate succinimidyl ester, Annexin V/propidium iodide, apoptosis

\section{Introduction}

Acute myeloid leukaemia (AML) has the highest mortality rate compared to the other major leukaemia types and accounts for $64 \%$ of deaths caused by leukaemia (1), due in part to its rapid progression. Mixed lineage leukaemia (MLL), a genetically distinct form of AML, is considered particularly aggressive with sufferers having poorer prognoses and earlier relapse-onset $(2,3)$. Although not as common as other types of cancer (4) relapsed AML cells may acquire additional mutations that render them refractory $(5,6)$. In the case of such aggressive relapsed leukaemia, it is desirable that alternative treatment should be obtained which can kill these cells. The current standard chemotherapy treatment regime for AML includes 7 days of cytarabine infusion combined with anthracycline drugs, such as doxorubicin or daunorubicin for the first 3 days.

Apoptosis (also known as programmed cell death I) is one of the main targets for the induction of cancer cell death with chemotherapeutic drugs. However, cancer cells have the potential to develop a mechanism with which to counteract apoptotic cell death, which contributes to their chemoresistance $(7,8)$. It has been suggested that some cancer cells develop chemoresistance through the modulation of autophagy. Autophagy is a cellular conservative process, using a catabolic 'self-cannibalising' mechanism, to either enhance cell survival or promote cell death $(9,10)$. Initially, the activation of autophagy was considered to be an adaptive response of malignant cells in cancer therapy, to develop resistance and promote survival (14). However, the overactivation of autophagy may lead to non-apoptotic cell death, known as programmed cell death II (10). Thus, under different conditions, autophagy acts as a guardian or executioner of tumour cells, via the promotion of chemoresistance and chemosensitivity, respectively $(9,10)$. The link between autophagy and other cell death types has been elucidated $(11,12)$ and in certain settings, autophagy inhibits apoptosis (13), facilitates/cooperates with apoptosis (14), or acts as an alternative cell death when apoptosis is blocked (9).

There is reportedly an interplay between Bcl-2 (an anti-apoptotic protein) and Beclin 1 (an autophagy marker), which can determine whether cells undergo apoptosis and/or autophagy (15-17). Blocking the Bcl-2/Beclin 1 complex at the endoplasmic reticulum level via the downregulation of $\mathrm{Bcl}-2$ 
leads to the upregulation of Beclin 1 with the activation of autophagy (17). Thus, Bcl-2 is involved in the regulation of both apoptosis and autophagy. The deregulation of the Bcl-2 protein in leukaemia may be one of the contributing factors of drug resistance against apoptotic cell death. Therefore, compounds targeting the $\mathrm{Bcl}-2$ protein family may increase patients' response to chemotherapy. In addition, bypassing apoptotic death by inducing other alternative cell death, such as autophagy, may prove to be a valuable mechanism in fighting refractory cancer cells.

The present study aimed to determine aspects of selectively induced cell death in AML by doxorubicin (Dox) through the modulation of apoptosis and autophagy. To the best of our knowledge, the present study reports for the first time that a p15-20-Bcl-2 protein is expressed in the AML MOLM-13 cell line in addition to the normal $\mathrm{p} 26-\mathrm{Bcl}-2-\alpha$ protein, but is absent in the leukaemic cell lines, OCI-AML2, U-937 and CML K562, which only express p26-Bcl-2- $\alpha$. The level of this novel p15-20-Bcl-2 isoform, but not the p26-Bcl-2- $\alpha$ level was inversely proportional to the concentration of Dox during the drug treatment. It was reported that Dox was found to exhibit a level of selectivity in inducing apoptotic cell death in the MOLM-13 and that this effect may be in part through the selective inhibition of the novel p15-20-Bcl-2.

\section{Materials and methods}

Cells and cell culture. SC (ATCC CRL-9855) cells were purchased from the American Type Culture Collection and maintained in Iscove's modified Dulbecco's medium (IMDM, Sigma-Aldrich; Merck KGaA). SC cells were originally monocytes from human peripheral blood, but have since been cross-contaminated by U-937 cells (ATCC CRL-1593.2). U-937 cells are derived from histiocytic lymphoma; leukaemia of the mononuclear phagocyte system consisting of monocyte/macrophage cells, which are myeloid in nature (18). Therefore, this cell line is referred to as the U-937 cell line in the present study. Authenticated leukaemic MOLM-13, OCI-AML2 and K562 cell lines (purchased from the European Collection of Cell Cultures, Public Health England) were maintained in Roswell Park Memorial Institute (RPMI)-1640 medium (Sigma-Aldrich; Merck KGaA). The MOLM-13 cell line is an immortalised AML cell line derived from MLL-rearranged cells from a relapsed patient with FLT3 mutation, which has evolved from myelodysplastic syndrome (19). This cell line allowed for the study of relapsed AML. OCI-AML2 is a cell line established from a patient acute myelomonocytic leukaemia, which carries DNMT3A R635W mutation. K562 was established from a patient in the blast crisis stage of chronic myelogenous leukaemia and positive for Philadelphia chromosome. Each type of complete culture medium was supplemented with $1 \%$ L-glutamine, $1 \%$ penicillin-streptomycin antibiotic and $10 \%$ fetal bovine serum (FBS, Sigma-Aldrich; Merck KGaA). All cell lines were tested regularly for mycoplasma using polymerase chain reaction. Cells were cultured and grown in a humidified incubator at $5 \% \mathrm{CO}_{2}$ environment and $37^{\circ} \mathrm{C}$. The leukaemic cell medium was changed every $48-72 \mathrm{~h}$ through cell pelleting by centrifugation (at room temperature at $260 \mathrm{x}$ g for $5 \mathrm{~min}$ ) followed by removing the old medium and replenishing with a fresh complete medium. Only cells in logarithmic growth were used in experiments. Trypan blue HyClone ${ }^{\circledR}$ dye assay was used to determine cell viability and cell density prior to proceeding with other assays. The cells were stained at a 1:1 ratio with the dye and manually counted using a haemocytometer under light microscopy. Cell viability of at least $97 \%$ was accepted as appropriate for experiments.

Cell death population assays using Alexa Fluor ${ }^{\circledR} 488$ Annexin V and PI: Flow cytometry. Cells $\left(1.0 \times 10^{6}\right.$ cells $\left./ \mathrm{ml}\right)$ were treated with Dox (final concentration, $0.5,1$ and $5 \mu \mathrm{M}$ dissolved in $0.05 \%$ DMSO) for $48 \mathrm{~h}$. Cells treated with $0.05 \%$ DMSO only were used as the vehicle control. Following the incubation period, cells were harvested, washed in cold PBS and then stained with Alexa Fluor ${ }^{\circledR} 488$ Annexin V (Thermo Fisher Scientific, Inc.) for $10 \mathrm{~min}$ followed by PI for a further $10 \mathrm{~min}$. They were analysed using a FACSCalibur flow cytometer (BD CellQuest ${ }^{\mathrm{TM}}$ Pro P software, BD Biosciences) at a fluorescent emission at $525 \mathrm{~nm}$ (FL1; Alexa Fluor ${ }^{\circledR}$ ) and $575 \mathrm{~nm}$ (FL3; PI) using $488 \mathrm{~nm}$ excitation wavelength. Alexa Fluor ${ }^{\circledR}$ uses Annexin V and propidium iodide (PI) to differentially stain and estimate cell population of viable and dead (necrotic and apoptotic) cells.

Determination of cell proliferation using 5(6)-carboxyfluorescein diacetate succinimidyl ester (CFSE)

Labelling cells with CFSE fluorescent dye. MOLM-13 cells were labelled with a cell membrane permeable fluorescent dye, CFSE prior to cell treatment. The cells were harvested, washed and re-suspended in phosphate buffer saline (PBS). A stock solution of CFSE ( $2 \mu \mathrm{M}$ in DMSO) was freshly diluted 100-fold in PBS for cell labelling. The cells were incubated in the dark with CFSE at room temperature for $20 \mathrm{~min}$ with shaking at $5 \mathrm{~min}$ intervals. The reaction was terminated by the addition of complete RPMI medium followed by pelleting of the cells. The cells were then re-suspended in fresh complete RPMI medium and incubated in the dark at $37^{\circ} \mathrm{C}$ for $10 \mathrm{~min}$ before being harvested and re-suspended at $1.0 \times 10^{6}$ cells $/ \mathrm{ml}$ with fresh complete RPMI medium. Cells not labelled with CFSE and not stained with PI were used as a blank control.

Cell treatments and PI staining. CFSE-labelled MOLM-13 cells (at $1.0 \times 10^{6}$ cells $/ \mathrm{ml} ; 950 \mu \mathrm{l}$ ) were treated with Dox (final conc. 0.5 and $1 \mu \mathrm{M}, 50 \mu \mathrm{l}$ ) in a 24-well plate. The treatments were incubated for 24,48 and $72 \mathrm{~h}$ in $5 \% \mathrm{CO}_{2}$ at $37^{\circ} \mathrm{C}$. Immediately before harvesting, $50 \mu \mathrm{l}$ fixed MOLM-13 cells were added to the CFSE-labelled cells and data obtained from the fixed cells were used for normalisation. For fixation, exponential growing unlabelled cells were harvested and washed in PBS and fixed in $0.4 \%$ paraformaldehyde $(0.5 \mathrm{ml})$ for $10 \mathrm{~min}$, washed and then re-suspended in PBS. Fixed cells (50 $\mu \mathrm{l}$; equivalent to $1.0 \times 10^{5}$ cells $/ \mathrm{ml}$ ) were added into each cell treatment. The treated cells containing fixed cells were then harvested, washed in flow buffer [PBS, 2\% FBS, 2 mM ethylenediaminetetraacetic acid (EDTA), $0.1 \%$ sodium azide], pelleted and stained with $0.5 \mu \mathrm{g} / \mathrm{ml}$ PI for $10 \mathrm{~min}$ in the dark at room temperature. Finally, flow buffer was added and the samples were analysed using FACSCalibur flow cytometry (BD CellQuest ${ }^{\mathrm{TM}}$ Pro software; BD Biosciences). Fluorescent detection was made at an emission wavelength of $480 \mathrm{~nm}$ (FL1 for CFSE) and $630 \mathrm{~nm}$ (FL3 for PI) using $488 \mathrm{~nm}$ excitation 
wavelength. Fixed cells stained only with PI were used as control.

Investigation of proteins involved in cell death: Western blot analysis

SDS-PAGE electrophoresis and membrane transfer. Protein concentrations in RIPA whole cell lysates from $48 \mathrm{~h}$ treatments with Halt Protease Inhibitor Cocktail (100X) (Thermo Fisher Scientific, Inc.) were quantified by Bradford assay. The lysates containing sample buffer (2X Laemmli loading buffer and a reducing agent, 5\% $\beta$-mercaptoethanol) were heated at $95^{\circ} \mathrm{C}$ for $5 \mathrm{~min}$. The reduced lysates $(30 \mu \mathrm{g})$ were separated by sodium dodecyl sulfate polyacrylamide electrophoresis (SDS-PAGE) using Mini-PROTEAN ${ }^{\circledR}$ TGX $^{\mathrm{TM}}$ (4-15\%) Precast gels (Bio-Rad Laboratories, Inc.) for 30-40 min at 100 volts. This was followed by protein transfer onto a nitrocellulose membrane by Trans-Blot ${ }^{\circledR}$ Turbo $^{\text {TM }}$ Transfer System (Bio-Rad Laboratories, Inc.).

Immunoblotting and visualisation. The transferred blots were blocked with 5\% BSA in $0.01 \%$ Tween-20 in PBS (PBS-T) with rocking for $1 \mathrm{~h}$ at room temperature and then washed 5 times in PBS-T. The blots were incubated with rocking overnight at $4^{\circ} \mathrm{C}$ with the following primary rabbit monoclonal antibodies in PBS-T with 5\% BSA: Anti-Bcl-2 (1:1,000; cat. no. ab32124), anti-Bax (1:1,000; cat. no. ab32503), or anti-Beclin 1 (1:2,000; cat. no. ab207612) (all from Abcam). Following the incubation period, the blots were washed 5 times in PBS-T and then probed with goat anti-rabbit $\operatorname{IgG}(\mathrm{H}+\mathrm{L})$ horseradish peroxidase secondary antibody in PBS-T with 5\% BSA (1:3,000; cat. no. 170-6515; Bio-Rad Laboratories, Inc.) for $1 \mathrm{~h}$ at room temperature and then washed 5 times in PBS-T. $\beta$-actin was used as a housekeeping protein control and detected using anti- $\beta$-actin mouse monoclonal $(1: 5,000$ in 5\% BSA; cat. no. ab8226; Abcam) followed by goat anti-mouse IgG $(\mathrm{H}+\mathrm{L})$ horseradish peroxidase-labelled secondary antibody (1:3,000 in 5\% BSA; cat. no. 170-6516; Bio-Rad Laboratories, Inc.). The blots were then incubated with ECL (Pierce $^{\mathrm{TM}}$ ECL Western Blotting Substrate) and the proteins visualised using ODYSSEY ${ }^{\circledR}$ FC imager (Li-Cor, Bioscience). A semi-quantitative comparison of protein levels was determined by densitometry using Image Studio ${ }^{\mathrm{TM}}$ Lite software.

Statistical analysis. Statistical analyses were performed using Minitab18 ${ }^{\circledR}$ statistical software. Assumptions of homogeneity of variance and underlying normality of distributions (all with 95\% coefficient interval) were tested using standard equal variance testing and the Anderson-Darling normality test as appropriate. A two-sample t-test was used to compare the means of two populations. One-way ANOVA was used to compare multiple means. Tukey (honest significant difference) post-hoc tests were then applied. Statistical significance was accepted with P-value $\leq 0.05$. The $\mathrm{IC}_{50}$ values of the drug were calculated by using GraphPad Prism 6 software, based on the mean \pm SE cell viability.

Data acquired from flow cytometric analyses of CFSE cell proliferation assays were analysed using Flowing Software (free flow cytometry data analysis software created by Perttu Terho, version 2.5.1). Cell population events were gated distinctively and back-gated to compensate for colour of Dox and auto-fluorescence. Distribution (cell population, y-axis) of the mean fluorescent intensity (MFI) shift within CFSE labelled cells (FL1-H, X-axis) was visualised using histograms. Since CFSE binds irreversibly to the mammalian cells it distributes $50 \%$ to each daughter cell every time a cell divides. MFI is therefore directly related to cell number. Thus, the cell population can be expressed as (Eqn. 1):

$$
\operatorname{MFI}(\mathrm{t})=\operatorname{MFI}(0) \exp (\alpha \mathrm{t})
$$

where $\operatorname{MFI}(\mathrm{t})$ represents the measure of $\mathrm{MFI}$ at time $\mathrm{t}, \mathrm{MFI}(0)$ is the fluorescence at the time of labelling $(t=0)$ and $\alpha$ is the growth rate when the cell population grows exponentially.

\section{Results}

Doxorubicin exhibits a level of selectivity in the induction of leukaemic cell death. The Dox-induced death of leukaemic monocytic cells was examined by flow cytometry. Apoptotic and necrotic cells were differentiated by the double-staining of MOLM-13 and U-937 cells with Annexin V and PI at following $48 \mathrm{~h}$ co-incubation of the cells with or without Dox (Fig. 1). The effect of therapeutically relevant concentrations of Dox $(0.5$ and $1 \mu \mathrm{M})$ was examined against the vehicle control (DMSO 0.05\%). A supraclinical dose of $5 \mu \mathrm{M}$ of Dox was used as a positive control.

Following $48 \mathrm{~h}$ co-incubation of cells with the treatments, the vehicle control treated-cells exhibited comparable cell death, with 25 and 21\% dead MOLM-13 and U-937 cells, respectively (with no statistically significant differences). In the treated MOLM-13 cells, including the vehicle control, the cell death populations resided more in early apoptosis $(\mathrm{P}=0.03$ for Dox $0.5 \mu \mathrm{M}$ and $\mathrm{P}<0.001$ for all other treatments compared to the U-937 cells) (Fig. 1A). By contrast, compared to the MOLM-13 cells, dead cells were predominantly found in late apoptosis in the $\mathrm{U}-937$ cells $(\mathrm{P}<0.01)$ apart from the cells treated with $1 \mu \mathrm{M}$ Dox, which exhibited a non-significant effect compared to the MOLM-13 cells, but was shown to be highly significant $(\mathrm{P}<0.01)$ compared to the vehicle control (Fig. 1B).

Cell death by necrosis was $<2 \%$ in all of the treated MOLM- 13 cells, whereas it ranged from $7-9 \%$ (in the $1 \mu \mathrm{M}$ Dox- and vehicle control-treated cells) to $37 \%$ (in the $5 \mu \mathrm{M}$ Dox-treated cells) in the U-937 cells (all $\mathrm{P}<0.05$ compared to the MOLM-13 cells). Thus, Dox induced MOLM-13 cell death in a dose-dependent manner through mainly early apoptotic death with minimal necrosis. However, it is noteworthy that the different concentrations of Dox induced the death of the U-937 cells by apparently different mechanisms. Dox $5 \mu \mathrm{M}$ induced death mainly by necrosis. A lower concentration of Dox, $0.5 \mu \mathrm{M}$, induced greater late apoptotic cell death and was more potent than treatment with $1 \mu \mathrm{M}$ Dox; the reason for this is currently uncertain. At therapeutically relevant concentrations, the MOLM-13 cells treated with Dox at 0.5 and $1 \mu \mathrm{M}$ exhibited $53 \%(\mathrm{P}<0.05)$ and $89 \%(\mathrm{P}<0.001)$ dead cells, respectively, compared to the vehicle control (Fig. 1). Comparatively, the U-937 monocytic cells exhibited fewer dead cells with a 1.3 -fold decrease in the $1 \mu \mathrm{M}$-treated cells $(\mathrm{P}<0.001$ compared to the MOLM-13 cells). The $\mathrm{IC}_{50}$ value of Dox following $48 \mathrm{~h}$ of co-incubation with MOLM-13 cells (based on the percentage of viable cell population) was lower compared to that for the U-937 monocytic cells (Fig. 1).

Doxorubicin decreases the proliferative rate of MOLM-13 cell lines. To further investigate the molecular mechanisms 


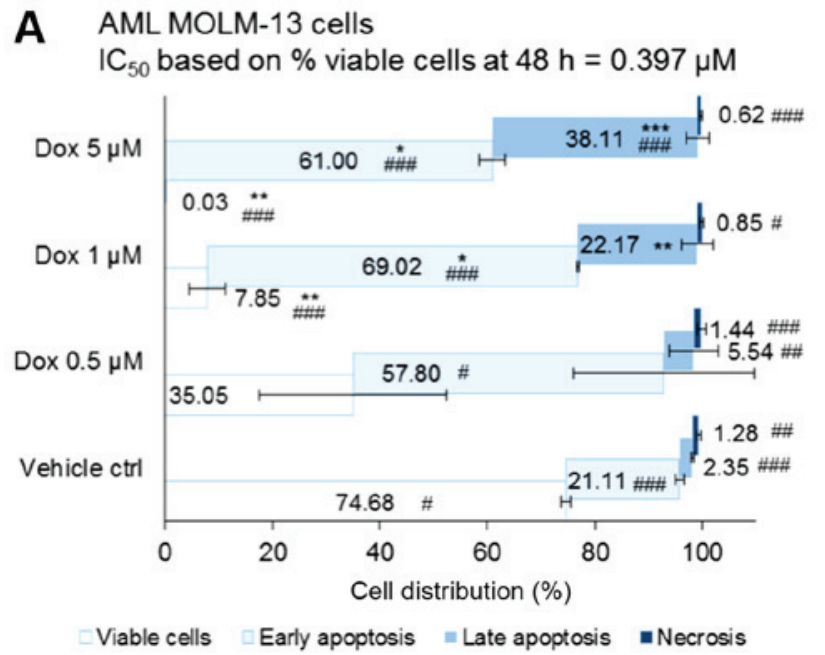

\section{B AML U-937 cells \\ $\mathrm{IC}_{50}$ based on \% viable cells at $48 \mathrm{~h}=0.658 \mu \mathrm{M}$}

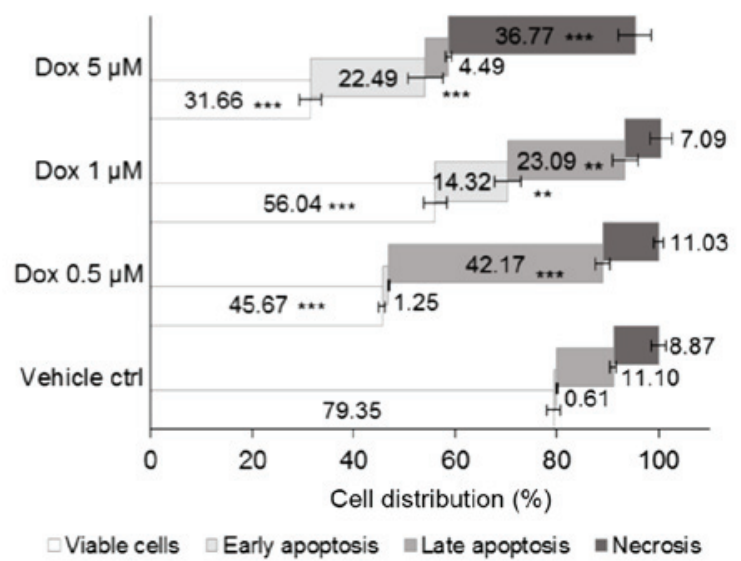

Figure 1. Cell death population of MOLM-13 and U-937 monocytic cells treated by Dox for $48 \mathrm{~h}$. Samples were double stained with Annexin V (apoptotic cell dye) and propidium iodide (PI, dead cell dye). (A) MOLM-13 cell line and (B) U-937 cells were treated with Dox (0.5, 1 and $5 \mu \mathrm{M})$ for $48 \mathrm{~h}$. Dox $5 \mu \mathrm{M}$ was used as the positive control drug and DMSO $0.05 \%$ was used as negative (vehicle) cell control. One-way ANOVA; Tukey's post-hoc test was used to compare live cells (-ve Annexin V and -ve PI) of the control and the treatments: $\mathrm{P}>0.05$, no significant difference (NSD); "P $\leq 0.05$. significant; * $\mathrm{P} \leq 0.01$, highly significant; ${ }^{* * *} \mathrm{P} \leq 0.001$, very highly significant. Dox demonstrated a level of selectivity in its cytotoxicity against MOLM-13 compared to U-937 cells (P<0.05). A two-sample t-test was used to compare cell population between MOLM-13 and $\mathrm{U}-937$ cells ( $\left.\mathrm{P}>0.05, \mathrm{NSD} ;{ }^{\# P} \mathrm{P} \leq 0.05 ;{ }^{\# \#} \mathrm{P} \leq 0.01 ;{ }^{\# \#} \mathrm{P} \leq 0.001\right)$. Results are expressed as the means $\pm \mathrm{SE}, \mathrm{n}=3$. Flowing software (version 2.5.1) was used to construct dot plots and gate cell populations as follows: Live cells (-ve Annexin $\mathrm{V}$ and -ve PI), early apoptosis (+ve Annexin V and -ve PI), late apoptosis (+ve Annexin V and +ve PI) and necrotic cells (-ve Annexin V and +ve PI).

A

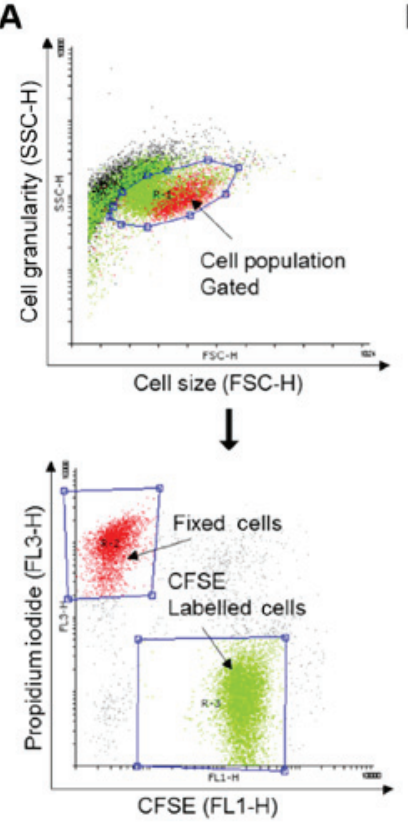

B a

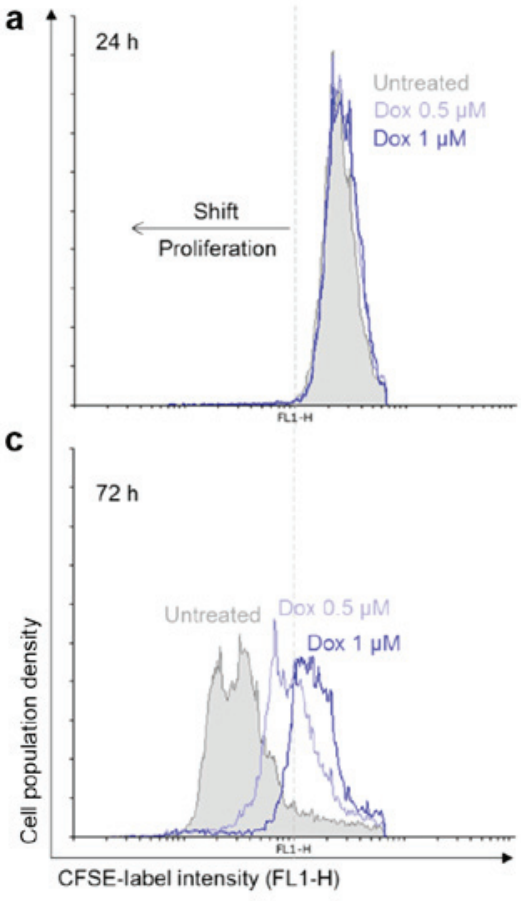

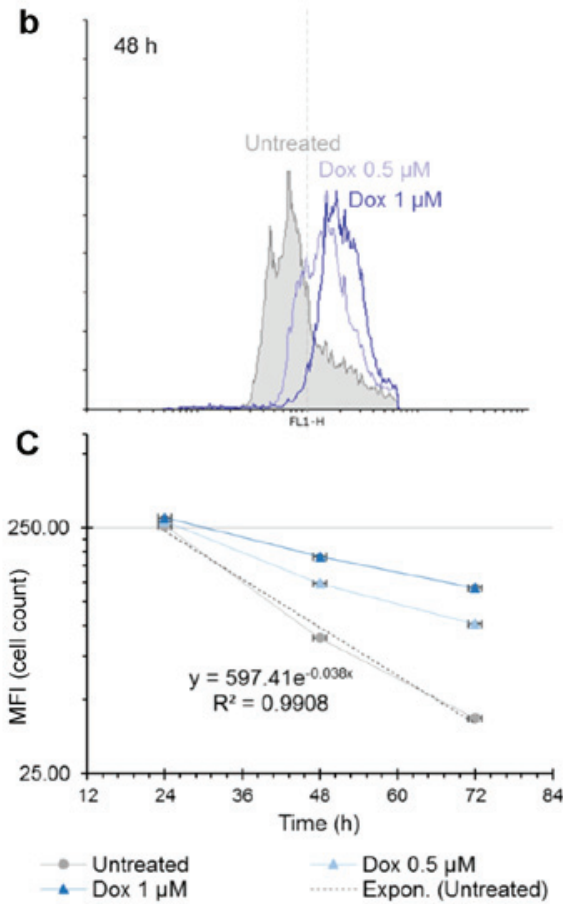

Figure 2. The anti-proliferative effect of doxorubicin on MOLM-13 cells. Cell proliferation was measured by CFSE assay. (A) Representative flow cytometry dot plots showing gating of CFSE labelled cell population. (B) Flowing software (version 2.5.1) was used to construct histogram overlay of treatments at (a) $24 \mathrm{~h}$, (b) $48 \mathrm{~h}$, and (c) $72 \mathrm{~h}$. (C) The MFI values of MOLM-13 after the treatments were plotted to generate the equation for doubling time, $\mathrm{n}=2$. CFSE, 5(6)-carboxyfluorescein diacetate succinimidyl ester.

of Dox-induced cell death, a single-cell assay based on CFSE tracker-labelled MOLM-13 cells was performed. CSFE binds covalently and irreversibly to free amino groups on proteins within cells and the fluorescence intensity of the dye halves with each cell division. Combined with live-dead staining, this allows not only to determine whether the drug affects the rate of cell division but also how the cells are dying. Fixed cells were positive for PI staining and were used to normalise the data (Fig. 2A). The number of MOLM-13 cells in the untreated cell samples doubled every $18 \mathrm{~h}$ (Fig. 2C). Following the 24-h incubation period, the control (untreated cells) and the Dox-treated samples all exhibited similar mean fluorescence intensity (MFI) values. The changes in the MFI at 48 and $72 \mathrm{~h}$ demonstrated that the rate of MOLM-13 cell proliferation 
A

Untreated

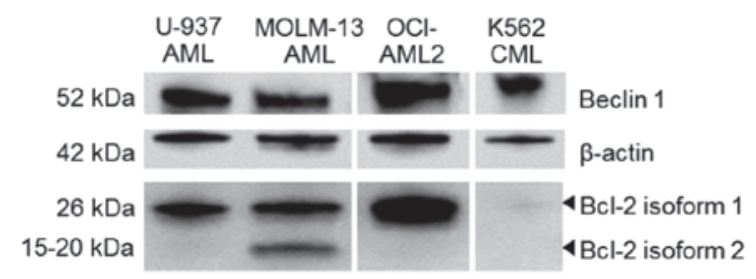

B

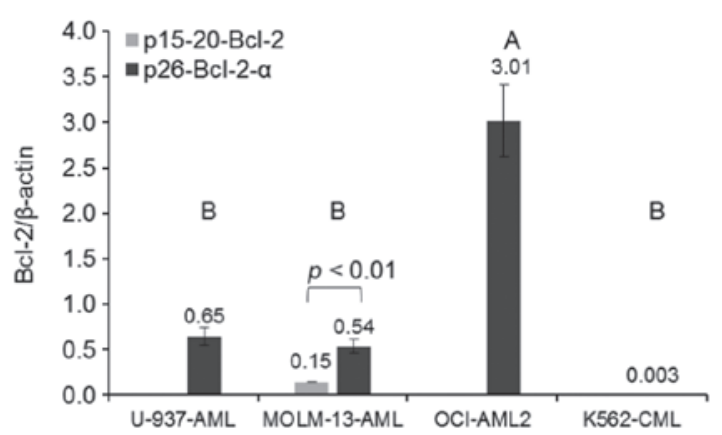

C
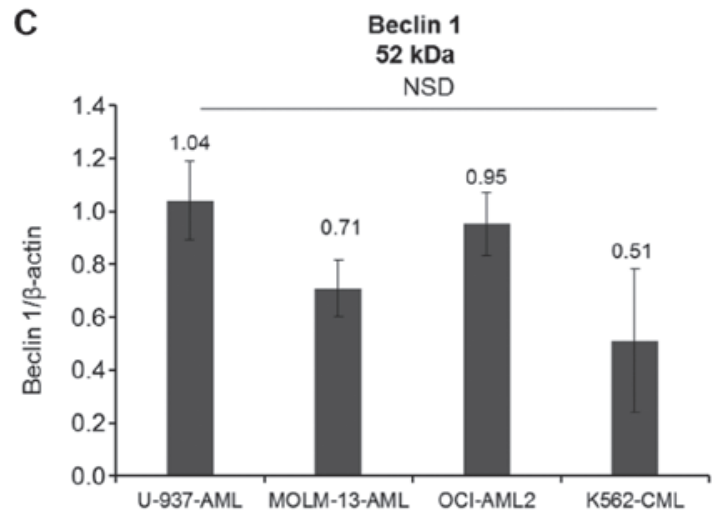

Figure 3. Bcl-2 and Beclin 1 protein expression levels in untreated cells. Western blot detection of proteins from whole cell lysates using $30 \mu \mathrm{g}$ protein loading of U-937, AML MOLM-13 and OCI-AML2 cells and CML K562. (A) Representative data image of a western blot. $\beta$-actin was used as a housekeeping protein. Basal protein expression of (B) anti-apoptotic Bcl-2 and (C) autophagy Beclin 1. Data are expressed as the mean \pm SE; $n=4$. One-way ANOVA; Tukey's post-hoc test was used for grouping and pairwise comparison. A two-sample t-test was used to compare the Bcl-2 isoforms in the MOLM-13 cell line.

was affected by Dox in a time- and concentration-dependent manner (Fig. 2B-b and -c). In the untreated cells, there was a shift to lower MFI values between the 24- and 72-h incubation time due to halving of the amount of the CFSE stain during each cell division cycle.

Doxorubicin selectively inhibits Beclin 1 and a novel Bcl-2 isoform exclusively expressed in the AML MOLM-13 cell line. To determine the molecular mechanisms of Dox-induced cytotoxicity in MOLM-13 cells, Bcl-2 and Beclin 1 protein levels were quantified by western blot analysis. Initial experiments on the expression of $\mathrm{Bcl}-2$ on MOLM-13 revealed two isoforms of the protein, estimated from the molecular weight of the proteins from the ladder control, to be $26 \mathrm{kDa}$ (p26-Bcl-2- $\alpha$ ) and $15-20 \mathrm{kDa}(\mathrm{p} 15-20-\mathrm{Bcl}-2)$. As p26-Bcl-2- $\alpha$ is the functional $\mathrm{Bcl}-2$ protein known to have anti-apoptotic effect and p15-20-Bcl-2 appear to be a novel isoform in MOLM-13, further experiments were conducted to determine if they were both present in other leukaemic cell lines containing different mutations. Unstressed AML cell lines (MOLM-13, OCI-AML2 and U-937 cells), as well as CML K562, all exhibited basal protein expression levels of the usually reported isoform of Bcl-2, p26-Bcl-2- $\alpha$ (Fig. 3). However, the expression of the protein was minimal in CML K562 cells. The OCI-AML2 cells exhibited the highest expression $(\mathrm{P}<0.001)$ of p26-Bcl-2- $\alpha$ when compared to the other cells. Of the cells tested, only the MOLM-13 cells contained the $15-20-\mathrm{Bcl}-2$ protein, but at lower levels compared to the $\mathrm{p} 26-\mathrm{Bcl}-2-\alpha$ protein $(\mathrm{P}<0.01)$. $\mathrm{Bcl}-2$ is an anti-apoptotic protein involved in cell death and interacts with an autophagy pathway through regulating Beclin 1 (16). The differences in the basal expression levels of Beclin 1 protein were not statistically significant $(\mathrm{P}>0.05)$ between the MOLM-13, OCI-AML2, CML K562 and U-937 cells.
Further experiments were conducted to determine if the p15-20-Bcl-2 isoform could be selectively targeted by drug therapy to induce cell death by comparing the effects of Dox on MOLM-13 and the U-937 cells. The expression of this novel p15-20-Bcl-2 protein was selectively inhibited in the Dox-treated MOLM-13 cells without any appreciable drug-specific effect on the expression of the p26-Bcl-2- $\alpha$ isoform in either MOLM-13 or U-937 cells (Fig. 4A-c and B-b). The p15-20-Bcl-2 protein levels in the MOLM-13 cells were significantly reduced by Dox $(\mathrm{P}<0.05)$ compared to the untreated control cells. Conversely, Dox inhibited the autophagic Beclin 1 protein levels by almost half at the higher concentrations tested with statistical significance shown for the effect of the $1 \mu \mathrm{M}$ concentration $(\mathrm{P}<0.05)$ (Fig. 4A-d). However, a non-significant $(\mathrm{P}>0.05)$ dose-dependent reduction trend of Beclin 1 was observed in the treated U-937 cells (Fig. 4B-c).

\section{Discussion}

The deregulation of the $\mathrm{Bcl}-2$ proteins in leukaemia may be one of the contributing factors of drug resistance against apoptotic cell death. Treatment of haematological malignancies have been shown to benefit from $\mathrm{BH} 3$-mimetics, which are compounds that promote the release of pro-apoptotic proteins from anti-apoptotic Bcl-2 effects (20). This leads to the induction of cell apoptosis. For instance, BH3-mimetic drugs such as venetoclax (ABT-199) enhance the effectiveness of available therapies for AML by inhibiting the overexpression of Bcl-2 seen in refractory leukaemia (21). Beclin 1 (an autophagy protein), is also a $\mathrm{BH} 3$-containing protein and, similar to some pro-apoptotic Bcl-2 members, it binds to the hydrophobic groove of $\mathrm{Bcl}-2$, making this interaction one of the 
A a

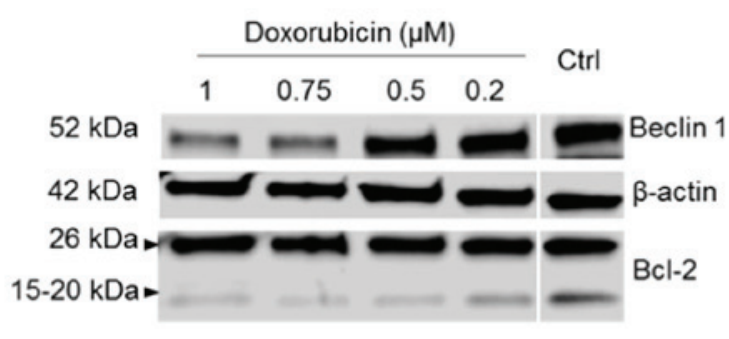

C

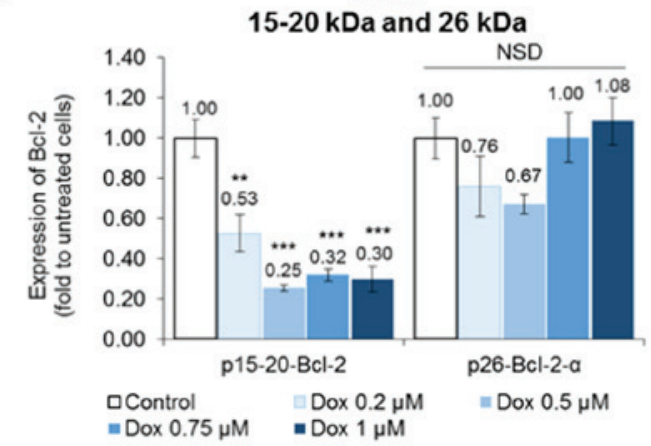

Dox-dependent expression
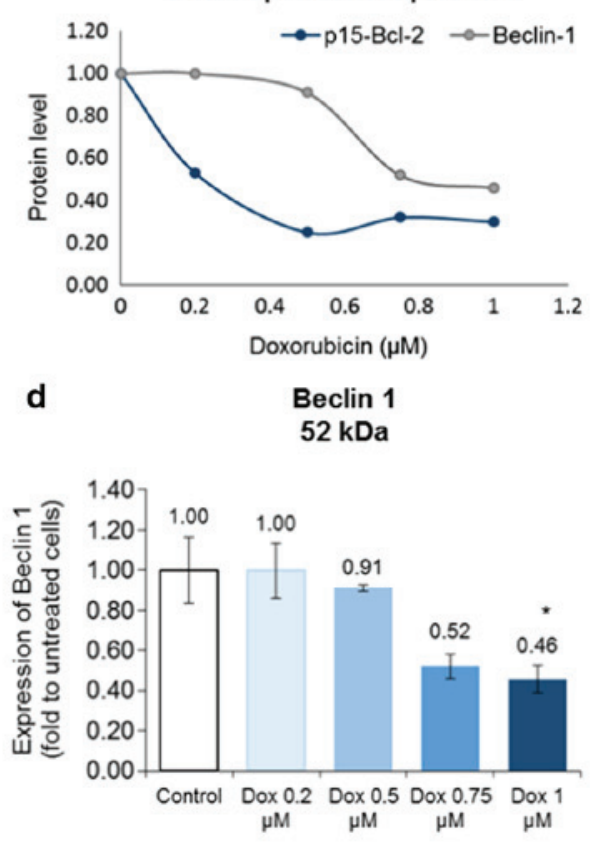

B a

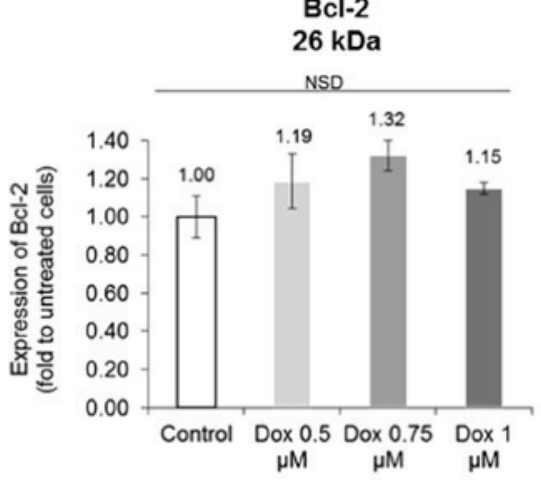

AML U-937 cells

Doxorubicin $(\mu \mathrm{M})$

\begin{tabular}{llll}
\hline & 0.75 & 0.5 & $C t r l$
\end{tabular}

$52 \mathrm{kDa}$

$42 \mathrm{kDa}$

$26 \mathrm{kDa}$

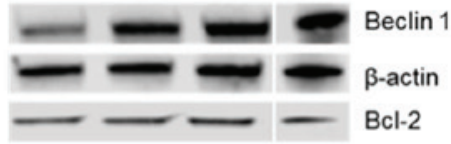

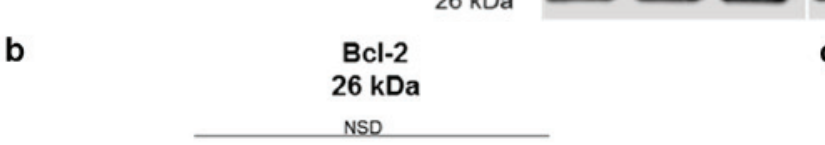

C Beclin 1

52 kDa

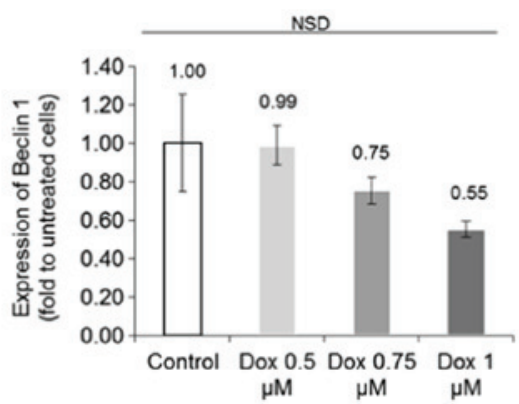

Figure 4. Bcl-2 and Beclin 1 protein expression levels in doxorubicin-treated U-937 and MOLM-13 cells. (A) MOLM13 and (B) U-937 cells were treated by Dox for $48 \mathrm{~h}$. (a) Representative western blot of $30 \mu \mathrm{g}$ protein loading (from whole cell lysates), using $\beta$-actin as a housekeeping protein. Quantitative analysis of proteins relative to $\beta$-actin normalised to untreated control: (A-c and B-b) Anti-apoptotic Bcl-2, (A-d and B-c) pro-autophagy marker Beclin 1, (A-b) Dox-dependent expression of p15-20-Bcl-2 and Beclin 1 protein levels. Data of proteins are expressed as the means \pm SE ( $n=3$ ) and analysed by One-way ANOVA; Tukey's post-hoc test. Statistical difference was accepted as following: $\mathrm{P}>0.05 \mathrm{~m}$ no significant difference; ${ }^{*} \mathrm{P} \leq 0.05$. significant; ${ }^{* *} \mathrm{P} \leq 0.01$, highly significant; ${ }^{* * *} \mathrm{P} \leq 0.001$, very highly significant.

regulatory mechanisms of autophagy (15). In the present study, Dox was evaluated on its potential to induce selective apoptotic cell death in AML MOLM-13 cells and to modulate autophagy through Bcl-2 and Beclin 1 protein expression levels.

Doxorubicin inhibits cell proliferation and exhibits a level of selective cell-death induction in MOLM-13 cells. The concentration of Dox in a patient's plasma within approximately $2 \mathrm{~h}$ of intravenous administration of the drug is $0.1-1 \mu \mathrm{M}(22)$. The documented effect of Dox as an anti-proliferative agent (23) was confirmed in the present study at 0.5 and $1 \mu \mathrm{M}$. However, Dox may not have a major effect on MOLM-13 during the first
24 h. Dox-treated MOLM-13 population decreased (relative to drug-free cell population) through a drug-induced reduction in the rate of proliferation in a time- and concentration-dependent manner (Fig. 2). It was also reported that Dox induced more cell death in the MOLM-13 than in U-937 cells ( $\mathrm{P}<0.05$; Fig. 1) indicating a certain level of selectivity of Dox toxicity on MOLM-13 cells, and this may be due to cell-dependent action of Dox.

In the literature, Dox has been reported to demonstrate a pleiotropic effect on cells ranging from affecting cell proliferation by binding to topoisomerase II (24) to inducing apoptosis by activating caspases (25-27) and disrupting mitochondrial 
membrane potential (28). In the search for the molecular mechanisms of Dox, further experiments were conducted to investigate the effect of the drug on members of the Bcl-2 family, the anti-apoptotic Bcl-2 and Beclin 1, an initiator of autophagy.

Doxorubicin inhibits the expression of a novel Bcl-2 protein variant in MOLM-13 cells. The BCL-2 gene has been reported to be upregulated in $84 \%$ of AML patients at diagnosis and the cases increase at relapse to $95 \%$ (29). MOLM-13, the cell line investigated in the present study, is derived from cells of a patient with relapsed AML (19). It was found that a novel Bcl-2 isoform variant of $15-20 \mathrm{kDa}(\mathrm{p} 15-20-\mathrm{Bcl}-2)$ was expressed in unstimulated leukaemic MOLM-13 cells (in addition to the usual $26 \mathrm{kDa}$ Bcl-2 protein), but not in other AML and CML cells tested in the present study (which only expressed p26-Bcl-2- $\alpha$ ) (Fig. 3). Anti-apoptotic Bcl-2 protein reduction by Dox has also been reported in HeLa cells (30) and breast cancer cells (31). In previous studies, the apoptosis inhibitory properties of $\mathrm{Bcl}-2$ have been credited to the main $\mathrm{p} 26-\mathrm{Bcl}-2-\alpha$ isoform, consisting of hydrophobic transmembrane region that can regulate mitochondria permeability $(32,33)$.

The phosphorylation status of $\mathrm{Bcl}-2$ protein family members defines the ability of the protein to regulate the death/survival of cells. Depending on the site of phosphorylation, the activation of the protein can be either enhanced or inhibited and these post-translational modifications can be modified by certain drugs. Alternative splicing variants of $\mathrm{p} 22-\mathrm{Bcl}-2$ creates distinct isoforms (32). Several alternative protein variants or isoforms of the Bcl-2 family members have been identified. However, the two main Bcl-2 proteins, encoded by the BCL-2 gene, have been documented as being $\mathrm{p} 26-\mathrm{Bcl}-2-\alpha$ and $\mathrm{p} 22-\mathrm{Bcl}-2-\beta$ which differ mainly in their carboxyl tails $(33,34)$. Despite the gene expression of $\mathrm{Bcl}-2-\alpha$ remaining dominant, the $\mathrm{Bcl}-2-\beta$ isoform levels have been found to be higher in chronic lymphocytic leukaemia patients compared to healthy patients (35). Alternative spliced Bcl-2 proteins have also been observed in other cancer cells. A study on thyroid tumours identified a protein isoform of $\mathrm{Bcl}-2$ at $21 \mathrm{kDa}$ alongside the standard $\mathrm{Bcl}-2$ phenotype (36). Another truncated Bcl-2 isoform, Bcl-2 $\Psi$ (psi) was found in invasive prostate cancer. This Bcl-2 $\Psi$ lacked a BH-3 domain which prevents dimerization with pro-apoptotic molecules (Bax and Bid) and thus protects cancer cells from cell death (37). In the present study, an isoform of Bcl-2 at 15-20 kDa was detected selectively in MOLM-13 cells. Messingerova et al (2015) also reported a Bcl-2 protein band at approximately $19 \mathrm{kDa}$ in an AML cross-resistance MOLM-13 cells (resistant to azacytidine), but the $26 \mathrm{kDa}$ isoform was absent (38). The authors of that study explained this finding as resulting from a Bcl-2 protein shift. However, they did not report further on the protein alteration linked to function. The present study reports a $\mathrm{Bcl}-2$ isoform similar in size as that reported by Messingerova et al (2015) and demonstrates that the isoform is a functional protein, which is selectively sensitive to Dox treatment in MOLM-13 cells. It is our opinion that the proteomic diversity of anti-apoptotic Bcl-2 in MOLM-13 cell lines may contribute to the oncogenic behaviour of the cancer. Understanding the different isoforms of Bcl-2, particularly those that are preferentially expressed in cancer cells, may be useful for developing specific drugs to target cells to induce cancer cell death.
Doxorubicin reduces Beclin 1, leading to cell death. The present study reported that the protein expression of Beclin 1 was reduced by Dox, but only at concentrations $>0.5 \mu \mathrm{M}$, with statistical significance for $1 \mu \mathrm{M}(\mathrm{P}<0.001)$ (Fig. 4A-d). It has been reported that depleting Beclin 1 by gene silencing augments mitochondrial permeabilisation and enhances Dox-induced apoptosis (39) and treatment with pharmacological and genetic inhibitors of autophagy augmented Dox-induced apoptotic cell death (40). In the present study, treatment with Dox led to a greater number of apoptotic MOLM-13 compared to U-937 cells, with an inhibition of p15-20-Bcl-2 and a concurrent inhibition of Bcl-2.

The interplay between Beclin 1 and Bcl-2 to regulate apoptosis and autophagy has also been documented by other researchers. The dissociation of this complex allows the activation of Beclin 1 to bind and form a complex with various proteins in initiating pre-autophaghosmal structure (17). Due to the ability of Bcl-2 protein to form a complex with Beclin 1, it also performs a role in regulating autophagy (16). Beclin 1 plays a crucial role in autophagy by forming vesicle nucleation and promoting the isolation membrane development through a complex of phosphatidyl inositol-3 kinase (PI3K) class III. Bcl-2 blocks autophagy by preventing Beclin 1 from facilitating the formation of the pro-autophagosome promoting complex. This leads to a decreased PI3K activity of Beclin 1-associated binding partner (41). Beclin 1 is also regulated by other autophagy proteins, such as Rubicon and Ambra $1(9,16)$. Similar to the findings in the present study, some researchers have reported that the reduction in autophagic proteins causes an increase in cell apoptosis (42). By contrast, Smuder et al (2011) reported that Dox treatments increased markers of autophagy, including Beclin 1 mRNA and protein levels in muscle tissues, which may have contributed to Dox-induced muscle toxicity (43). In addition, Beclin 1 levels increased time-dependently in multiple myeloma cell lines when treated by Dox (40). Therefore, increases in autophagy proteins in some cells could be an adaptive response to drug-induced stress for survival initiated by dying cells and inhibition of these proteins result in death (40). Although the role of autophagy in cancer is yet to be confirmed, there is a possibility of its modulation and usefulness in cancer therapy.

The present study reports initial findings of a larger project examining the interplay between autophagic and apoptotic proteins and how they can be modulated by drug treatments to induce selective cell death in cancer cells. In the present study, the AML cell line, MOLM-13, expressed a Dox-regulated p15-20-Bcl-2 isoform in addition to the usual p26-Bcl-2- $\alpha$ isoform of which expression levels are unaffected. The induction of cell death in MOLM-13 by Dox may also be due to its modulation of Beclin 1. Further studies are warranted to determine if p15-20-Bcl-2 can be selectively targeted by drugs to induce cell death in MOLM-13 cells.

Studies are currently underway using apoptosis or autophagy inhibitors for further verification of the association between Dox-induced apoptosis and autophagy. Other studies include the investigation of a wider panel of autophagic and apoptotic proteins in different cell lines, as well as primary patient cells and non-leukaemic cells to study the interplay between the two pathways. The study of Bcl-2 in these cells is a matter of priority. Recommended future work will also 
investigate Beclin 1/Bcl-2 complexes by immunoprecipitation with anti Beclin-1 followed by western blot analysis with anti-Bcl-2 to provide some insight into the interactions of the two proteins. In addition, other studies are warranted, including proteomic and genomic studies to provide more accurate determination of the novel Bcl-2 variant in MOLM-13. Confirmation studies, such as sodium dodecyl sulfate protein separation with Coomassie staining followed by time-of-flight mass spectrometry could validate the distinct isoform. Other studies may include immuno-precipitation followed by proteolytic fragmentation and time-of-flight mass spectrometry to identify deletion and altered splicing. Knockout experiments, as well as, cloning the p15-20-Bcl-2 isoform, transfecting it into suitable cell lines and purifying to analyse association with other proteins using western blot analysis are also proposed to evaluate the role of the protein. qPCR analysis with different primer sets may be used to study the relative gene expression levels of BCL-2 in MOLM-13 and other cell lines.

\section{Acknowledgements}

The authors would like to thank Dr Huw Jones and Dr Steve Kett both of Middlesex University (UK), for proofreading the manuscript.

\section{Funding}

No funding was received.

\section{Availability of data and materials}

The datasets used and/or analyzed during the current study are available from the corresponding author on reasonable request.

\section{Authors' contributions}

MV and SA conceived, designed, performed the experiments, analysed, interpreted and wrote the manuscript with significant contributions from NK and CB. RO and TL were involved in the design, acquisition, analysis, interpretation and revision of the manuscript. All the authors read and approved the final version of the manuscript.

\section{Ethics approval and consent to participate}

Not applicable.

\section{Patient consent for publication}

Not applicable.

\section{Competing interests}

The authors declare that they have no competing interests.

\section{References}

1. Cancer Research UK: Leukaemia (all subtypes combined) statistics. Cancer Research UK, Oxford, 2016. https://www. cancerresearchuk.org/health-professional/cancer-statistics/ statistics-by-cancer-type/leukaemia
2. Lun Y, Yang JJ and Wu Y: Complete molecular remission in relapsed and refractory acute myeloid leukaemia with MLL-AF9 treated with chidamide-based chemotherapy. J Clin Pharm Ther 42: 786-789, 2017.

3. Daigle SR, Olhava EJ, Therkelsen CA, Majer CR, Sneeringers CJ, Song J, Johnston LD, Scott MP, Smith JJ, Xiao Y, et al: Selective killing of mixed lineage leukemia cells by a potent small-molecule DOT1L inhibitor. Cancer Cell 20: 53-65, 2011.

4. Hassan C, Afshinnekoo E, Li S, Wu S and Mason CE: Genetic and epigenetic heterogeneity and the impact on cancer relapse. Exp Hematol 54: 26-30, 2017.

5. Madanat YF, Kalaycio ME and Nazha A: Advances in acute myeloid leukemia genomics, where do we stand in 2018? Acta Med Acad 48: 35-44, 2019.

6. Ding L, Ley TJ, Larson DE, Miller CA, Koboldt DC, Welch JS, Ritchey JK, Young MA, Lamprecht T, McLellan MD, et al: Clonal evolution in relapsed acute myeloid leukaemia revealed by whole-genome sequencing. Nature 481: 506-510, 2012.

7. Zahreddine $\mathrm{H}$ and Borden KLB: Mechanisms and insights into drug resistance in cancer. Front Pharmacol 4: 28, 2013.

8. Hu X and Xuan Y: Bypassing cancer drug resistance by activating multiple death pathways - a proposal from the study of circumventing cancer drug resistance by induction of necroptosis. Cancer Lett 259: 127-137, 2008.

9. Nikoletopoulou V, Markaki M, Palikaras K and Tavernarakis N: Crosstalk between apoptosis, necrosis and autophagy. Biochim Biophys Acta 1833: 3448-3459, 2013.

10. Ouyang L, Shi Z, Zhao S, Wang FT, Zhou TT, Liu B and Bao JK: Programmed cell death pathways in cancer: A review of apoptosis, autophagy and programmed necrosis. Cell Prolif 45: 487-498, 2012.

11. Radogna F, Dicato M and Diederich M: Cancer-type-specific crosstalk between autophagy, necroptosis and apoptosis as a pharmacological target. Biochem Pharmacol 94: 1-11, 2015.

12. Goodall ML, Fitzwalter BE, Zahedi S, Wu M, Rodriguez D, Mulcahy-Levy JM, Green DR, Morgan M, Cramer SD and Thorburn A: The autophagy machinery controls cell death switching between apoptosis and necroptosis. Dev Cell 37: 337-349, 2016.

13. Liang J, Shao SH, Xu ZX, Hennessy B, Ding Z, Larrea M, Kondo S, Dumont DJ, Gutterman JU, Walker CL, et al: The energy sensing LKB1-AMPK pathway regulates p27(kip1) phosphorylation mediating the decision to enter autophagy or apoptosis. Nat Cell Biol 9: 218-224, 2007.

14. Ding WX, Ni HM, Gao W, Hou YF, Melan MA, Chen X, Stolz DB, Shao ZM and Yin XM: Differential effects of endoplasmic reticulum stress-induced autophagy on cell survival. J Biol Chem 282: 4702-4710, 2007.

15. Decuypere JP, Parys JB and Bultynck G: Regulation of the autophagic bcl-2/beclin 1 interaction. Cells 1: 284-312, 2012.

16. Marquez RT and Xu L: Bcl-2:Beclin 1 complex: multiple, mechanisms regulating autophagy/apoptosis toggle switch. Am J Cancer Res 2: 214-221, 2012.

17. Lian J, Karnak D and Xu L: The Bcl-2-Beclin 1 interaction in (-)-gossypol-induced autophagy versus apoptosis in prostate cancer cells. Autophagy 6: 1201-1203, 2010.

18. Usmani S, Sivagnanalingam U, Tkachenko O, Nunez L, Shand JC and Mullen CA: Support of acute lymphoblastic leukemia cells by nonmalignant bone marrow stromal cells. Oncol Lett 17: 5039-5049, 2019.

19. Matsuo Y, MacLeod RA, Uphoff CC, Drexler HG, Nishizaki C, Katayama Y, Kimura G, Fujii N, Omoto E, Harada M, et al: Two acute monocytic leukemia (AML-M5a) cell lines (MOLM-13 and MOLM-14) with interclonal phenotypic heterogeneity showing MLL-AF9 fusion resulting from an occult chromosome insertion, ins(11;9)(q23;p22p23). Leukemia 11: 1469-1477, 1997.

20. Gomez-Bougie P, Maïga S, Tessoulin B, Bourcier J, Bonnet A, Rodriguez MS, Le Gouill S, Touzeau C, Moreau P, Pellat-Deceunynck $\mathrm{C}$, et al: $\mathrm{BH} 3$-mimetic toolkit guides the respective use of BCL2 and MCL1 BH3-mimetics in myeloma treatment. Blood 132: 2656-2669, 2018.

21. Campos EdV: Pinto R: Targeted therapy with a selective BCL-2 inhibitor in older patients with acute myeloid leukemia. Hematology. Transfus Cell Ther 41: 169-177, 2019.

22. McHowat J, Swift LM, Arutunyan A and Sarvazyan N: Clinical concentrations of doxorubicin inhibit activity of myocardial membrane-associated, calcium-independent phospholipase $\mathrm{A}(2)$. Cancer Res 61: 4024-4029, 2001.

23. Rudolfová $P$, Hanušová V, Skálová L, Bártíková H, Matoušková $P$ and Boušová I: Effect of selected catechins on doxorubicin antiproliferative efficacy and hepatotoxicity in vitro. Acta Pharm 64: 199-209, 2014. 
24. Fornari FA, Randolph JK, Yalowich JC, Ritke MK and Gewirtz DA: Interference by doxorubicin with DNA unwinding in MCF-7 breast tumor cells. Mol Pharmacol 45: 649-656, 1994.

25. Inoue-Yamauchi A, Jeng PS, Kim K, Chen HC, Han S, Ganesan YT, Ishizawa K, Jebiwott S, Dong Y, Pietanza MC, et al: Targeting the differential addiction to anti-apoptotic BCL-2 family for cancer therapy. Nat Commun 8: 16078, 2017.

26. Florou D, Patsis C, Ardavanis A and Scorilas A: Effect of doxorubicin, oxaliplatin, and methotrexate administration on the transcriptional activity of BCL-2 family gene members in stomach cancer cells. Cancer Biol Ther 14: 587-596, 2013.

27. Panaretakis T, Pokrovskaja K, Shoshan MC and Grandér D: Activation of Bak, Bax, and $\mathrm{BH} 3$-only proteins in the apoptotic response to doxorubicin. J Biol Chem 277: 44317-44326, 2002.

28. Gamen S, Anel A, Pérez-Galán P, Lasierra P, Johnson D, Piñeiro A and Naval J: Doxorubicin treatment activates a Z-VAD-sensitive caspase, which causes deltapsim loss, caspase-9 activity, and apoptosis in Jurkat cells. Exp Cell Res 258: 223-235, 2000.

29. Moon JH, Sohn SK, Lee MH, Jang JH, Kim K, Jung CW and Kim DH: BCL2 gene polymorphism could predict the treatment outcomes in acute myeloid leukemia patients. Leuk Res 34: 166-172, 2010

30. Bien S, Rimmbach C, Neumann H, Niessen J, ReimerE, Ritter CA, Rosskopf D, Cinatl J, Michaelis M, Schroeder HW, et al: Doxorubicin-induced cell death requires cathepsin B in HeLa cells. Biochem Pharmacol 80: 1466-1477, 2010.

31. Pilco-Ferreto $\mathrm{N}$ and Calaf GM: Influence of doxorubicin on apoptosis and oxidative stress in breast cancer cell lines. Int J Oncol 49: 753-762, 2016.

32. Akgul C, Moulding DA and Edwards SW: Alternative splicing of Bcl-2-related genes: Functional consequences and potential therapeutic applications. Cell Mol Life Sci 61: 2189-2199, 2004.

33. Guillem V, Amat P, Collado M, Cervantes F, Alvarez-Larrán A Martínez J,TormoE,Eroles P, Solano Cand Hernández-Boluda JC: BCL2 gene polymorphisms and splicing variants in chronic myeloid leukemia. Leuk Res 39: 1278-1284, 2015.

34. Tanaka S, Saito K and Reed JC: Structure-function analysis of the $\mathrm{Bcl}-2$ oncoprotein. Addition of a heterologous transmembrane domain to portions of the $\mathrm{Bcl}-2$ beta protein restores function as a regulator of cell survival. J Biol Chem 268: 10920-10926, 1993.
35. Ghassemifar R, Forster L, Finlayson J, Calogero T, Augustson B, Joske D and Cull G: Differential expression of the Bcl-2 and Bax isoforms in CD19 positive B-lymphocytes isolated from patients diagnosed with chronic lymphocytic leukaemia. Pathology 44: 632-637, 2012

36. Manetto V, Lorenzini R, Cordon-Cardo C, Krajewski S, Rosai J, Reed JC and Eusebi V: Bcl-2 and Bax expression in thyroid tumours. An immunohistochemical and western blot analysis. Virchows Arch 430: 125-130, 1997.

37. Huang JM, Lin TY, Chang D, Lin SL and Ying SY: Truncated Bcl-2, a potential pre-metastatic marker in prostate cancer. Biochem Biophys Res Commun 306: 912-917, 2003.

38. Messingerova L, Imrichova D, Kavcova H, Turakova K, Breier A and Sulova Z: Acute myeloid leukemia cells MOLM-13 and SKM-1 established for resistance by azacytidine are crossresistant to P-glycoprotein substrates. Toxicol In Vitro 29: 1405-1415, 2015.

39. Daniel F, Legrand A, Pessayre D, Vadrot N, Descatoire V and Bernuau D: Partial Beclin 1 silencing aggravates doxorubicin- and Fas-induced apoptosis in HepG2 cells. World J Gastroenterol 12: 2895-2900, 2006.

40. Pan Y, Gao Y, Chen L, Gao G, Dong H, Yang Y, Dong B and Chen $\mathrm{X}$ : Targeting autophagy augments in vitro and in vivo antimyeloma activity of DNA-damaging chemotherapy. Clin Cancer Res 17: 3248-3258, 2011.

41. Pattingre S, Tassa A, Qu X, Garuti R, Liang XH, Mizushima N, Packer M, Schneider MD and Levine B: Bcl-2 antiapoptotic proteins inhibit Beclin 1-dependent autophagy. Cell 122: 927-939, 2005

42. Boya P, González-Polo RA, Casares N, Perfettini JL, Dessen P, Larochette N, Métivier D, Meley D, Souquere S, Yoshimori T, et al: Inhibition of macroautophagy triggers apoptosis. Mol Cell Biol 25: 1025-1040, 2005.

43. Smuder AJ, Kavazis AN, Min K and Powers SK: Exercise protects against doxorubicin-induced markers of autophagy signaling in skeletal muscle. J Appl Physiol (1985) 111: 1190-1198, 2011.

This work is licensed under a Creative Commons Attribution-NonCommercial-NoDerivatives 4.0 International (CC BY-NC-ND 4.0) License. 